
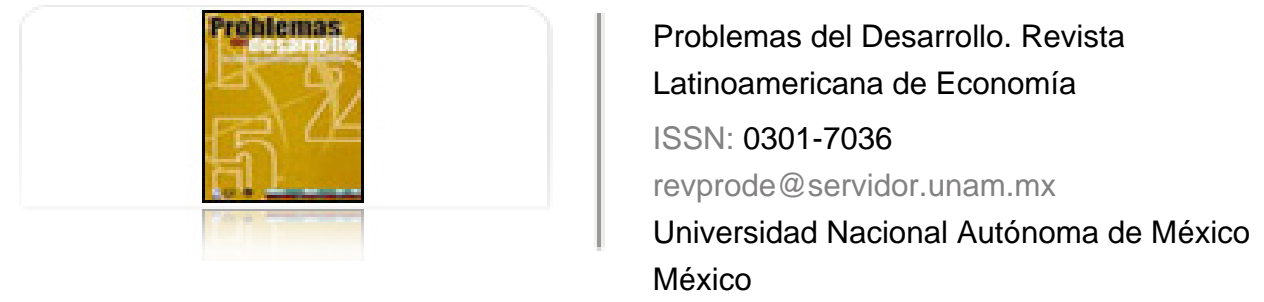

Avendaño Ruiz, Belem; Schwentesius Rindermann, Rita

Factores de competitividad en la producción y exportación de hortalizas: el caso del valle de Mexicalli, B.C., México

Problemas del Desarrollo. Revista Latinoamericana de Economía, vol. 36, núm. 140, 2005, pp. 165-

192

Universidad Nacional Autónoma de México

Distrito Federal, México

Disponible en: http://www.redalyc.org/articulo.oa?id=11820092008

- Cómo citar el artículo

- Número completo

- Más información del artículo

Página de la revista en redalyc.org

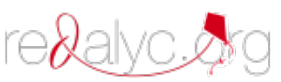

Sistema de Información Científica

Red de Revistas Científicas de América Latina, el Caribe, España y Portugal Proyecto académico sin fines de lucro, desarrollado bajo la iniciativa de acceso abierto 


\section{FACTORES DE COMPETITIVIDAD EN LA PRODUCCIÓN Y EXPORTACIÓN DE HORTALIZAS: EL CASO DEL VALLE DE MEXICALI, B.C., MÉXICO*}

\section{Belem Avendaño Ruiz** Rita Schwentesius Rindermann ${ }^{\star \star \star}$}

Fecha de recepción: 17 de marzo 2004. Fecha de aceptación: 24 de mayo de 2004.

\section{Resumen}

Se analizan los principales cambios que los productores han puesto en práctica en la actividad hortícola del valle de Mexicali como una condición fundamental para su permanencia en el mercado internacional. Dicha actividad en esta región surgió para complementar la producción estadounidense y, a partir de los años cincuenta, buscó la consolidación de su presencia en el mercado de aquel país mediante contratos agrícolas y de comercialización. A la fecha, los productores controlan la cadena de producción mediante una integración vertical que les permite garantizar procesos productivos inocuos; no así en la cadena de valor, en la cual sólo alcanzan eslabones de producción, empaque y embarque, pues la comercialización permanece casi en su totalidad en manos estadounidenses.

Palabras clave: competitividad, mercado internacional, cambio tecnológico, inocuidad alimentaria.

* Este trabajo representa al segundo lugar en el premio "M tro. Ricardo Torres Gaitán 2003" y se otorgó a las autoras como parte del mejor trabajo de los investigadores y estudiosos de la economía mexicana residentes en el territorio nacional, exceptuando el D.F.

* Coordinadora de Posgrado e Investigación de la Facultad de Economía de la Universi dad Autónoma de Baja California, Tijuana, México. Correo electrónico: belem_avendano@yahoo.com

La autora agradece al dr. Fernando Cer vantes Escoto y a Luis Ginocchio Balcázar por sus contribuciones al revisar este documento. A los productores de hortalizas y princi pales protagonistas de este ensayo, Ernesto M oreno M oreno, Ismael Vargas Pérez, Ramón Santillán Perea y Carmen Quintana Samano.

* Directora del Centro de Investigaciones Económicas, Sociales y Tecnológicas de la Agroindustria y la Agricultura M undial (CIESTAAM ), Universidad Autónoma Chapingo. Correo electrónico: rsr@ avantel.net 


\section{Abstract}

The paper analyzes the principal changes which the producers themselves have set in motion in horticultural activities in the Mexicali valley, as a fundamental condition for their continued presence in the international market. This activity in the region emerged to complement U.S. production and, from the 1950s onwards, sought to consolidate its presence in that country's market via agricultural and selling contracts. At the same time, the producers control the production chain through vertical integration, allowing them to guarantee nontoxic production processes. This is not the case with the value-chain, in which they only achieve production, packaging and loading links, because selling remains almost entirely in U.S. hands.

Key terms: competitiveness, international market, technological change, non-toxic foodstuffs.

\section{Résumé}

On analyse les principaux changements mis en place par les producteurs eux-mêmes dans l'activité d'horticulture de la vallée de Mexicali comme une des conditions fondamentales pour la permanence de cette région dans le marché international. Cette activité a surgi pour compléter la production américaine et, à partir des années cinquante, elle a cherché la consolidation de sa présence dans le marché américain au moyen de contrats agricoles et de commercialisation. A ce jour, les commerçants contrôlent la chaîne de production au moyen d'une intégration verticale qui leur permet de garantir des procédés productifs inoffensifs; ce qui n'est pas le cas dans la chaîne de valeur, dans laquelle ils n'atteignent que peu de maillons de production, d'emballage et d'embarquement, car la commercialisation demeure presque dans sa totalité aux mains des américains.

Mots clés: compétitivité, marché international, changement technologique, innocuité alimentaire.

\section{Resumo}

Analizam-se as principais mudanças que os proprios produtores têm posto em prática na atividade hortícola no vale de Mexicali como uma condição fundamental para a sua permanência no mercado internacional. Tal atividade nesta região surgiu para complementar a produção dos Estados Unidos e, a partir dos anos 50, procurou a consolidação da sua presença no mercado daquele país mediante contratos agrícolas e de comercilização. $\mathrm{Na}$ atualidade os produtores controlam a cadeia de produção por meio de uma integração vertical que permite-lhes garantir processos produtivos inócuos; não assim na cadeia de valor, na qual só alcançam elos de produção, embalagem e embarque, pois a comercialização continua, quase na sua totalidade, nas mãos dos Estados Unidos.

Palavras chave: competitividade, mercado internacional, mudança tecnológica, inocuidade alimentária.

\section{DeSarrollo}




\section{Introducción}

$\mathrm{E}$

$\mathrm{n}$ el valle de Mexicali, Baja California, al noroeste de México, las hortalizas

comenzaron a cosecharse en los años sesenta con vocación exportadora. La cerca

nía con el mercado estadounidense, la ventaja absoluta derivada del menor costo de la mano de obra mexicana respecto de la de Estados Unidos, la disposición de agua y la orientación agrícola del valle propiciaron la incorporación de los productores locales al contexto internacional. En el valle, la producción se concentra en el ciclo otoño-invierno, cuando el clima es adverso en el país vecino y sus necesidades de abastecimiento son crecientes. Autores como Hernández (2002) y Ranfla (1987) afirman que la producción de hortalizas en Mexicali no se inició de manera independiente, sino vinculada a la producción misma en los estados de California y Arizona, y de manera complementaria, para consolidar la oferta en el mercado estadounidense.

Lo anterior ha llevado a los productores del valle a actuar con diligencia en la adopción de tec-nología de punta y de modificaciones en el proceso productivo, en el uso de insumos de alta calidad, en la organización para la toma de decisiones a fin de continuar su participación en el mercado internacional, en el cumplimiento de los más altos estándares de calidad y sanidad. Además de la realización de transformaciones que les permitan controlar cada una de las fases, desde la preparación de la tierra hasta el manejo poscosecha, empaque y embarque de los productos al mercado de exportación, integrándose verticalmente en estas etapas, lo cual ha posibilitado su permanencia a lo largo de treinta años en uno de los mercados más competitivos y exigentes del mundo, el estadounidense.

A pesar de que los productores han logrado una reducción sustancial de los costos de producción, han mantenido la calidad y sanidad y, ahora, la inocuidad de sus productos,

Cuadro 1

Ingredientes del éxito de los productores de hortalizas del valle de Mexicali

\begin{tabular}{lll}
\hline \multicolumn{1}{c}{ Ingrediente } & \multicolumn{1}{c}{ Detalle } & Resultado \\
\hline Tecnología de punta & $\begin{array}{c}\text { Semillas, procesos, insumos, riego, } \\
\text { empaque, equipos, poscosecha }\end{array}$ & Máxima calidad \\
$\begin{array}{l}\text { Organización para la toma } \\
\text { de decisiones }\end{array}$ & Sistema Producto Cebollín & Control de superficie \\
Sanidad e inocuidad & Certificaciones & Confiabilidad \\
Traceabilidad & Control de cada fase & Confiabilidad \\
Integración vertical & Control de calidad \\
Diversificación de mercados & Mercado orgánico, justo & Confiabilidad \\
\end{tabular}

\section{$\underline{\text { DeSarerrollo }}$}


han fracasado en el intento de lograr una mayor participación dentro de la cadena de comercialización que favorezca la obtención de mayores ingresos en esta etapa.

En este trabajo se realiza un análisis de los principales cambios producidos en la actividad hortícola del valle de Mexicali, que han permitido a sus productores ser altamente competitivos en el mercado internacional; también se examina la composición de la cadena productiva, así como sus principales fortalezas, debilidades, amenazas y oportunidades.

\section{La competitividad}

Contreras (2000) define la competitividad como un concepto ajeno a la teoría económica, referente a la situación real que presenta un producto en un mercado (internacional) distorsionado, tanto por fallas de éste como por la intervención de los gobiernos. La competitividad, entonces, se refiere al nivel de rentabilidad privada de un producto, a su capacidad de participar exitosamente en el mercado internacional, de acuerdo con los precios de mercado existentes.

La competitividad de un producto en este mercado depende de: $a$ ) sus ventajas comparativas asociadas con factores naturales favorables y menores costos relativos en la producción; $b$ ) la estructura y los costos de transporte y comercialización hasta el lugar donde será expendido. Además, su relación competitividad-precio en los mercados externos se ve influida por los movimientos de la tasa de cambio. Su competitividad también se ve afectada por otros factores: la calidad y el grado de diferenciación del producto, la estacionalidad de la producción y el mercado, y las políticas gubernamentales, tanto del país exportador como del importador. Esta mayor competitividad se expresa en el crecimiento de las exportaciones y en un aumento de su participación en dicho mercado.

\section{La competitividad en el nivel macroeconómico}

En el nivel macroeconómico existen dos enfoques para medir empíricamente la competitividad:

1. Usar indicadores directos mediante comparaciones de costos de producción en regiones y/o países competidores, ajustados por los costos de transporte y comercialización y por las tasas de cambio.

2. Medir la competitividad por medio de indicadores indirectos, tales como la participación de mercado o algún índice de ventaja comparativa revelada, con la conveniencia de que estos indicadores pueden estimarse utilizando estadísticas de comercio.

Uno de los indicadores más usados para medir las ventajas comparativas reveladas (o ventaja competitiva) es el desarrollado por Vollrath (1991): ${ }^{1}$ si el índice de ventaja relativa

1 Este concepto, introducido por Vollrath, mide las ventajas comparativas reveladas o ventajas competitivas para productos agrícolas específicos, usando información de datos real es de comercio.

\section{$\underline{\text { DeSarrofrollo }}$}


de exportación (VRE) es positivo o mayor que 1 (VRE $>1$ ), indica que el país presenta ventaja comparativa revelada en dicho producto, y si es menor que 1 o negativo (VRE $<1$ ), el país presenta una desventaja comparativa. Además, mientras más elevado sea el valor del índice, mayor será el grado de especialización del país en este producto y, por tanto, mayor su competitividad.

En el caso de México, el subsector de frutas y hortalizas presentó un índice vRE positivo, pero decreciente a lo largo del periodo 1990-2001 (Figura 1 y Cuadro 2).

A pesar de que las exportaciones de hortalizas tuvieron una tasa anual de crecimiento de $7.8 \%$ entre 1990 y 2001, su competitividad en el mercado internacional es decreciente.

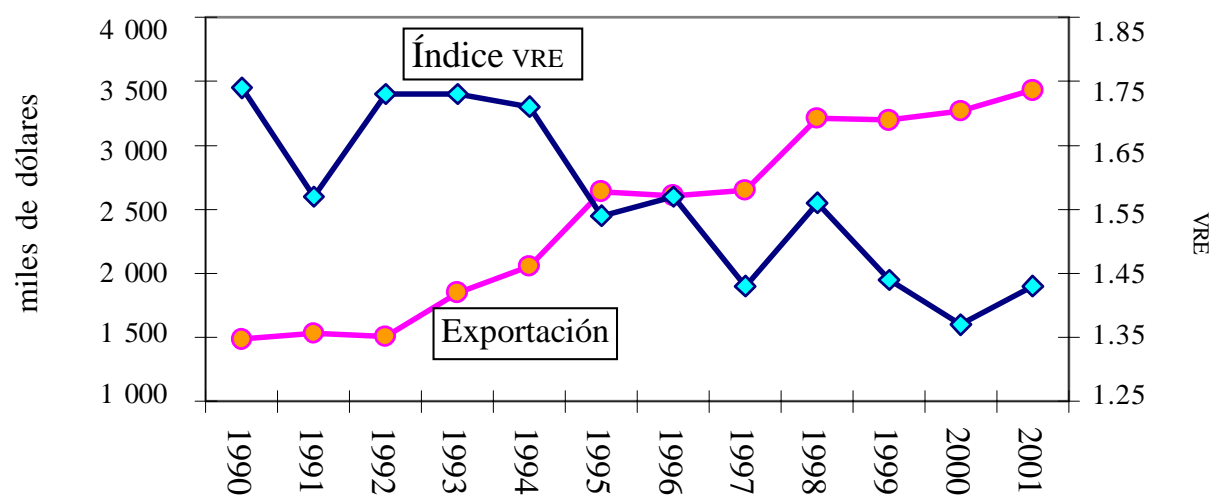

Figura 1. Exportación de frutas y hortalizas (1 000 dólares) e índice de VRE, 1990-2001, México.

Fuente: elaboración propia con base en datos de FAO, Faostat, en http://apps.fao.org

Cuadro 2

Índice de ventaja relativa de las exportaciones de frutas y hortalizas y productos seleccionados en el mercado mundial, 1990-2001, México

\begin{tabular}{|c|c|c|c|c|c|c|c|c|c|}
\hline Año & $\begin{array}{c}\text { Frutas y } \\
\text { hortalizas }\end{array}$ & Ajo & Espárrago & Tomate & Cebolla & Pepino & Pimiento & Melón & Fresa \\
\hline 1990 & 1.74 & 1.55 & 2.22 & 3.52 & 2.62 & 2.76 & 3.18 & 3.13 & 1.26 \\
\hline 1991 & 1.57 & 1.86 & 2.45 & 2.82 & 2.88 & 2.64 & 2.65 & 3.28 & 1.21 \\
\hline 1992 & 1.73 & 1.85 & 2.51 & 2.66 & 3.09 & 2.86 & 3.08 & 2.98 & 0.74 \\
\hline 1993 & 1.73 & 1.85 & 2.50 & 3.15 & 2.93 & 2.56 & 3.00 & 2.08 & 1.17 \\
\hline 1994 & 1.71 & 1.32 & 2.35 & 2.94 & 2.68 & 3.01 & 2.82 & 2.20 & 1.48 \\
\hline 1995 & 1.54 & 1.50 & 2.63 & 3.11 & 2.51 & 2.70 & 2.80 & 2.20 & 1.50 \\
\hline 1996 & 1.57 & 2.04 & 2.88 & 3.01 & 2.84 & 2.70 & 2.59 & 2.03 & 1.79 \\
\hline 1997 & 1.43 & 1.66 & 3.09 & 2.87 & 2.61 & 2.52 & 2.83 & 2.53 & 0.98 \\
\hline 1998 & 1.56 & 1.97 & 3.30 & 2.90 & 2.26 & 2.67 & 2.78 & 2.29 & 1.67 \\
\hline 1999 & 1.44 & 1.59 & 3.78 & 2.65 & 2.36 & 2.53 & 2.62 & 2.30 & 1.57 \\
\hline 2000 & 1.37 & 1.14 & 3.60 & 2.31 & 2.67 & 2.70 & 2.84 & 2.08 & 1.45 \\
\hline 2001 & 1.43 & 1.26 & 2.54 & 2.48 & 2.47 & 2.79 & 2.90 & 1.98 & 1.23 \\
\hline
\end{tabular}

Fuente: elaboración propia con base en datos de FAO, Faostat, en http://apps.fao.org 
Como se puede observar, el índice VRE, para el subsector en su conjunto, alcanzaba un valor de 1.74 en 1990, presenta un periodo de relativa estabilidad de 1992 a 1994 y a partir de este año, fecha en que entró en vigor el Tratado de Libre Comercio con Estados Unidos y Canadá, inicia su decrecimiento, sin recuperación aparente por el resto del periodo, cuando era de esperarse que debido al TLC, las exportaciones de frutas y hortalizas de México se hubiesen incrementado y su competitividad fortalecido. A primera vista, México no se ha beneficiado sustancialmente con ese tratado y la pérdida de competitividad se puede apreciar tanto en el nivel agregado, para todo el sub-sector, como para los principales productos exportados (Cuadro 2).

Los principales productos hortícolas que México exporta son tomate, ajo, espárrago, cebolla, pepino, pimiento, melón y fresa; concentran $48 \%$, en promedio, de las exportaciones mexicanas realizadas en los últimos diez años. Sin embargo, la competitividad presentada por cada uno de ellos es diferente, ya que algunos productos, como el tomate, tienen una larga historia en el mercado internacional, al iniciar exportaciones desde 1904. Otros productos se han ido incorporando a la oferta exportable: pepino, pimiento, fresa y berenjena.

Con respecto al índice de competitividad, productos como tomate, cebolla, pimiento, melón y berenjena alcanzaron niveles mayores a 3.0 del índice VRE; otros, como espárrago, pepino y pimiento, 2.0 pero consistentes, en tanto fresa y ajo mostraban los índices menores. A partir de 1994, todos los productos presentan disminución en el índice VRE, a excepción de espárrago y fresa y, a partir de 1998, la tendencia cambia para ajo, tomate, pepino, pimiento, fresa y berenjena, cuando el índice cae nuevamente.

Por todo lo anterior se puede concluir, de acuerdo con ambas metodologías, que las exportaciones de frutas y hortalizas frescas mexicanas son competitivas en el mercado mundial; no obstante, nuestro país ha disminuido su especialización en esos productos, debido probablemente a la diversificación de las exportaciones con el tiempo.

\section{La competitividad en el nivel microeconómico}

Con relación a las organizaciones y las empresas, los factores del entorno microeconómico que afectan la competitividad pueden agruparse en tres grandes categorías: la tecnología, el entorno en el cual se desarrollan las actividades económicas y la disponibilidad de servicios especializados de apoyo a la producción y la distribución, en tanto que dentro del entorno macroeconómico tienen influencia las medidas e instrumentos de política globales, como son las monetaria, fiscal y cambiaria (Colmenares, 1996:43-52).

En el caso de este análisis, la pregunta que surge es: ¿cuáles son los factores que influyen en la competitividad de la producción y exportación de hortalizas en la región de Mexicali? A manera de hipótesis, se plantea que los factores que permitieron el desarrollo competitivo de los productores de hortalizas del valle de Mexicali están íntimamente

\section{DeSarrollo}


ligados con el entorno microeconómico o de la empresa. Es decir, los productores han realizado acciones que repercuten directamente en su desempeño empresarial, mientras que los factores macroeconómicos propiciados por la política de Estado han tenido poca o nula influencia como impulsores de la competitividad.

\section{Antecedentes}

En el valle de Mexicali la producción de hortalizas — cebollín, espárrago, trigo, algodón y alfalfa - se ha convertido en una de las principales actividades económicas. Su orientación exportadora la sitúa como una importante generadora de empleo y divisas. De las 230000 ha susceptibles de cultivo en el valle, se dedican a la producción agrícola alrededor de 160 000, de las cuales en el año agrícola 2001, 44.54\% fueron ocupadas por trigo, cultivo de mayor presencia en cuanto a superficie sembrada, pero no así en producción, al ser superado por los forrajes, que aportan $77.38 \%$ del volumen total de producción del valle (Cuadro 3).

Cuadro 3

Distribución de la producción por tipo de cultivo y principales indicadores económicos, 2001, valle de Mexicali, B.C.

\begin{tabular}{lrrrrrrr}
\hline \multirow{2}{*}{ Producto } & \multicolumn{2}{c}{ Superficie } & \multicolumn{2}{c}{ Producción } & \multicolumn{2}{c}{ Valor } \\
& hectáreas & $\%$ & \multicolumn{2}{c}{ toneladas } & $\%$ & miles de pesos & $\%$ \\
\hline Trigo & 68341 & 44.54 & 384099 & 13.38 & 438991 & 20.37 \\
Forrajes & 43742 & 28.51 & 2221120 & 77.38 & 540704 & 25.10 \\
Algodón & 23903 & 15.58 & 85081 & 2.96 & 155849 & 7.23 \\
Hortalizas & 13163 & 8.58 & 145666 & 5.07 & 917627 & 42.60 \\
Otros & 4286 & 2.79 & 34205 & 1.21 & 101261 & 4.7 \\
\hline Total & 153435 & 100.00 & 2870171 & 100.00 & 2154431 & 100.00 \\
\hline
\end{tabular}

Fuente: elaboración propia con datos de la delegación de la SAGARPA en Baja California, en Anuario estadístico municipal de Mexicali, segunda versión (Coplademm, 2002).

La importancia de la producción de hortalizas radica en la generación de: a) valor, al aportar $42.60 \%$ del total de la producción del valle; $b$ ) divisas, al orientarse a la exportación alrededor de $90 \%$ de la producción, y c) empleo, ya que genera cerca de 15000 empleos directos, principalmente durante el ciclo agrícola otoño-invierno. ${ }^{2}$

2 Información proporcionada por el ingeniero Ernesto M oreno M oreno, productor de hortalizas del valle de Mexicali y director de la Compañía Agrícola Omega, S. de R.L. de C.V., comunicación personal sostenida en 2003.

\section{$\underline{\text { DeSarerrollo }}$}




\section{Incorporación del valle de Mexicali a la producción agrícola}

Según Stamatis (1993), en la evolución geológica, el valle Imperial ${ }^{3}$ dio vida al de Mexicali. A principios del siglo xx, la sociedad de irrigación Terrenos de Baja California, filial de Mexican Land and Colonization Company, construyó allí un sistema de canales, el cual, por las características del terreno, se desarrolló primero del lado mexicano, usando mano de obra fundamentalmente asiática para la realización de la obra y para los trabajos agrícolas.

El desarrollo económico del valle de Mexicali y de la propia ciudad se produjo gracias a la siembra de algodón, el cual fue por muchos años el principal cultivo generador de valor y empleo agrícola en la zona, hasta que fue desplazado por el cebollín que, a la fecha, persiste como el de mayor importancia económica.

El patrón de cultivos evolucionó del monocultivo del algodón a la producción de forrajes y hortalizas; estas últimas tomaron gran auge a partir de la caída internacional de los precios de las fibras naturales en la década de los setenta (Stamatis, op. cit.). Entre las principales hortalizas de exportación del valle de Mexicali destaca el cebollín, el cual se cultiva principalmente para el consumo de sus hojas, ya que el bulbo no se desarrolla. Por eso se le conoce como cebolla verde.

El inicio de la agricultura de exportación en el valle de Mexicali está ligado a las operaciones emprendidas por productores de hortalizas de Estados Unidos, cuyas actividades comprendían desde el cultivo hasta la comercialización. Dichos productores encontraron en el clima y el suelo de algunas regiones de México las ventajas competitivas para trasladar o complementar las operaciones que desarrollaban en su propio país, o en otras regiones. Sin embargo, en los años setenta se fortaleció la presencia de compañías distribuidoras dedicadas básicamente al embarque y la comercialización de las hortalizas, con poca integración hacia la producción agrícola y poca participación en este último rubro.

El principal ejemplo de este proceso es el cultivo de tomate, que se inició en Sinaloa por el interés de los comercializadores del este de Estados Unidos de encontrar una zona de producción para abastecerse en los meses de invierno y así complementar el abasto doméstico para todo el año. Actualmente, como consecuencia de esta acción, el tomate es uno de los principales productos agrícolas de exportación de México.

En el caso de Baja California, la zona de la costa fue desarrollada por comercializadores de California, Estados Unidos, que encontraron condiciones climatológicas similares a las de su estado para la producción de tomate, además de menores costos de producción, sobre todo por la mano de obra, la cual representó mayores ventajas competitivas en comparación con las propias y favoreció la producción en la zona.

3 Valle ubicado al norte de Caléxico, California, en la frontera con M exicali. En algunos estudios, cuando se habla de valle Imperial, se refiere tanto al que se encuentra del lado de California y Arizona, como al de Baja California y Sonora.

\section{DeSRarrollo}




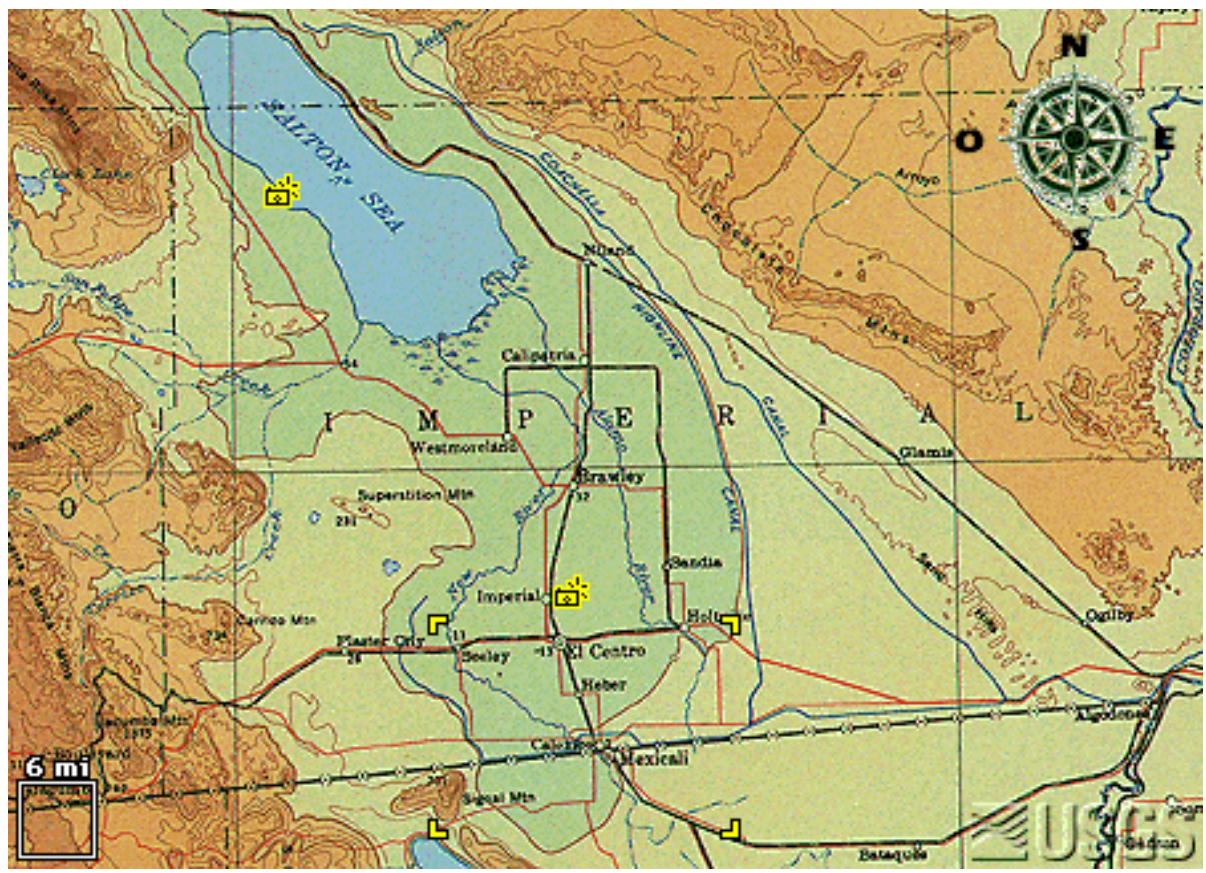

Mapa 1. Valles de Mexicali e Imperial.

Fuente: www.bajatelecom.com.mx/coberturas.htm

En el valle de Mexicali, sufrieron este proceso el espárrago y el cebollín. Hernández (2002) expone que este último vino a sustituir la producción de los estados de California y Arizona. El inicio de su producción en Mexicali fue la razón por la que desapareció su cultivo en Estados Unidos, principalmente en el ciclo otoño-invierno.

\section{El inicio de la producción de hortalizas para la exportación}

Hernández (op. cit.) ubica el inicio de la producción de hortalizas en el valle de Mexicali en los años sesenta, cuando se establecieron siembras de variedades de cebolla para bulbo en pequeños huertos y se cosechaban en estado inmaduro (verde) para el mercado local.

El primer programa comercial destinado al mercado de exportación se inició en el ciclo otoño-invierno de 1965-1966 en la colonia Pescaderos, pero no fue sino hasta que se estableció la Empresa Legumbres de Baja California, S.A. — con siembras en el ciclo otoño-invierno de 1971-1972 en la colonia Silva—, que el cultivo empezó a tener importancia económica.

A fines de la década de los años ochenta, la producción de hortalizas representaba $1.5 \%$ de los productores, $5 \%$ de la superficie cosechada y el agua, $25 \%$ del valor de la producción y $34 \%$ de la ocupación agrícola, sin considerar la etapa de poscosecha (Stamatis, op. cit.:64); para entonces, prácticamente toda la producción se destinaba al consumo en

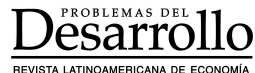


fresco y para la exportación. Respecto de la tipología de los agricultores, Stamatis encontró que del total de 267 productores de hortalizas $56 \%$ eran pequeños y no presentaban diversificación de cultivos, ya que sólo cosechaban una especie hortícola (melón tardío), cultivaban $6.5 \%$ de la superficie un promedio de 4.5 ha, y su producción se destinaba casi en su totalidad al mercado doméstico. Los medianos representaban $16 \%$ del total de productores de hortalizas, tenían al menos un producto de exportación de un rango de dos a cinco especies hortícolas, cultivaban $12 \%$ de la superficie, con un promedio de 48.5 ha, en tanto las empresas grandes representaban $27.5 \%$ de los productores, se caracterizaban por una elevada diversificación de la producción, de seis a diez productos, de los cuales destinaban por lo menos uno a la exportación (cebollín, espárrago, ajo) y poseían en promedio 1151 ha por unidad de producción.

Los productores de hortalizas de exportación no tenían capacidad de distribución en el mercado estadounidense ni en ningún otro externo, por lo que la comercialización de sus productos dependía directamente de las compañías estadounidenses. Por lo anterior, Stamatis (ibid.) consideró que la producción de exportación en el valle de Mexicali, desde su surgimiento hasta fines de los años ochenta, se basó en los contratos de producción. ${ }^{4}$

En ese tiempo, $83.5 \%$ de las empresas grandes y 50\% de las medianas recibían insumos - consistentes en semilla y material de empaque-, por parte de su distribuidor, a la vez que la totalidad de los grandes productores y $75 \%$ de los medianos recibían un flujo de servicios financieros por parte del mismo distribuidor. El productor obtenía su pago cuando la producción se vendía y los ingresos netos llegaban con la liquidación, es decir, se le asignaban una vez descontadas las facturas de venta, el financiamiento, los insumos y la comisión por concepto de comercialización; así, sus ingresos alcanzaban entre 10\% y 15\% del valor de las ventas.

En esta etapa no había una gran integración a lo largo de todo el proceso, incluyendo el empaque y el transporte. En el caso de los productores medianos, 50\% de éstos entregaban su producción libre a bordo (LAB) en empaque y en $50 \%$ restante la entrega era LAB en frontera. En el caso de los grandes productores, $83.5 \%$ entregaba a algunas compañías distribuidoras (localizadas en Estados Unidos), y 16.5\%, LAB en frontera. Así, la mayoría de las empresas grandes contaba con infraestructura de refrigeración tanto en el empaque como en el transporte, en tanto que las empresas medianas sólo contaban con refrigeración en el empaque. Ninguna empresa local disponía en esa fecha de infraestructura y servicios de distribución, lo cual les hubiera permitido acceder al último eslabón en la cadena de comercialización de sus productos e incrementar su participación en el valor agregado.

4 Stamatis define el contrato de producción como aquella relación en la que, además de compraventa entre productor y distribuidor, existen relaciones hacia atrás, lo cual confirmó al analizar los flujos de servicios financieros y de insumos de la compañía extranjera hacia el productor mexicano, y de productos de este último hacia la primera.

\section{DeSRarrollo}




\section{Los años noventa y la consolidación de la producción hortícola}

La importancia de la producción de hortalizas en el valle de Mexicali creció y se consolidó al paso de los años. A inicios de la década de los noventa, el valle fue atacado por la plaga de mosquita blanca, lo cual dejó fuera de la actividad hortícola a las pequeñas unidades que se dedicaban a la producción de melón tardío para el mercado nacional. En esta época la producción para exportación se generó en treinta empresas medianas y grandes, que sembraban cebollín y lo empacaban, principalmente con destino a los mercados de Estados Unidos y Canadá, así como del Reino Unido en Europa.

Se puede considerar que esta consolidación fue fruto de la prórroga de los contratos de producción y del fortalecimiento de la relación entre el capital estadounidense y el nacional. Es importante mencionar que en el proceso de desarrollo de esta actividad, la capitalización permitió a algunos de los productores mexicanos llegar a independizarse financieramente de sus asociados estadounidenses y operar por cuenta propia, mediante la adopción de la tecnología de producción y el paquete cultural requerido por el mercado de destino.

Durante el periodo 1990-1997, la producción y el traslado de hortalizas se encontraban sujetos a la expedición de permisos, lo cual facilitaba el control de la superficie y de la oferta. La Unión Nacional de Organismos de Productores de Hortalizas y Frutas (UNPH) ${ }^{5}$ tenía la concesión del Gobierno Federal para manejar la expedición de permisos de siembra de cultivos hortícolas y la de certificados para el traslado de estos productos. Así, la siembra y la comercialización de hortalizas del país estaban bajo el control de este organismo, el cual estableció como primer requisito para ser sujeto de la obtención de éstos, estar afiliado al mismo. A partir de entonces, en el nivel local se constituyeron las asociaciones agrícolas y las uniones agrícolas regionales que conformaron la estructura de la UNPH, que posteriormente cambió su razón social a Confederación Nacional de Productores de Hortalizas (CNPH), hoy casi extinta.

Actualmente, en el estado de Baja California existen dos organismos que agrupan a productores de hortalizas: la Unión Agrícola Regional de Productores de Hortalizas del Valle de Mexicali (UARPhvm) y la Unión Agrícola Regional de Productores de Legumbres de la Zona Costa del Estado de Baja California.

La apertura comercial de México consiguió la eliminación de los permisos previos, ${ }^{6}$ como las concesiones para controlar los permisos de siembra y los certificados de origen, cuya anulación en 1988 significó el inicio de la decadencia de la CNPH y, con ello, la invalidación de los elementos de inspección para el sostén de los organismos afiliados, por lo cual desapareció la mayoría de ellos. La liberación del requisito de permiso previo para

5 En 1989 cambiaría a Confederación Nacional de Organismos Productores de Hortalizas.

6 Esto llevó a la liberación del requisito de permiso previo para cualquier tipo de cultivo y de productor, tanto nacionales como extranjeros.

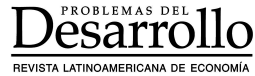


la producción de cualquier tipo de cultivo y la reforma al artículo 27 constitucional, que permitió la entrada de la inversión extranjera directa en la agricultura, trajo como consecuencia inmediata el establecimiento de mayor cantidad de empresas dedicadas a esta actividad, que entraron en competencia con las ya establecidas.

En Baja California, la libertad en la producción y el acceso de extranjeros a la agricultura tuvieron un impacto inmediato, reflejado en el incremento de la superficie dedicada a los cultivos hortícolas, especialmente el cebollín, y provocó una sobreoferta y un desplome en el nivel de precios en el mercado estadounidense, principal destino de este producto.

La incursión de la inversión extranjera directa se registró de dos maneras mediante: 1) el establecimiento de nuevas y grandes empresas ${ }^{7}$ que realizaron operaciones hortícolas con capital 100\% estadounidense, y 2) algunas empresas de ese país que operaban en el valle por medio de productores mexicanos, al terminar su relación con éstos, se instalaron en la región para continuar con la producción y operación directa del cultivo. ${ }^{8}$ Estos divorcios, aunados al asentamiento de nuevas empresas, ocasionaron la fragmentación de la producción en mayor demanda de superficie agrícola y número de empresas.

Así, en este periodo se localizaban en el valle cerca de 200 agricultores de hortalizas, $86 \%$ de los cuales eran pequeños productores de melón tardío para el mercado nacional; éstos, como consecuencia de la plaga de la mosquita blanca (de la cual este cultivo es hospedero), quedaron fuera del mercado hortícola, con excepción de los que tenían pequeñas siembras de tomatillo y chiles para el consumo local y regional. Así, la producción de exportación quedó restringida a cerca de 30 empresas, de las cuales $8 \%$ eran medianas, cultivaban una superficie inferior a 100 ha con cebollín, y $6 \%$ eran empresas grandes, con áreas promedio mayores a las 300 ha sembradas de cebollín y otros cultivos.

El efecto inmediato de la desregulación de la actividad se aprecia en la superficie establecida para el cultivo de cebollín durante el ciclo 1988-1989, la cual se incrementó cerca de $34 \%$ con respecto al ciclo anterior, como se observa en la Figura 2. Sin embargo, el mercado inició su ajuste y, a partir del ciclo agrícola 1990-1991, esta área se redujo sustancialmente, para retomar un comportamiento un tanto errático, íntimamente ligado a la oferta en el mercado estadounidense y al precio recibido por los productores mexicanos.

Los ciclos agrícolas 1992-1993 y 1993-1994 representaron una dura prueba de permanencia, al enfrentar una severa crisis de precios ocasionada por el incremento de la superficie establecida para la siembra del cebollín y una sobreoferta del producto en el merca-

7 Empresas como Sahara, Promotora Agrícola El Toro y Estrella Nueva absorben a sus socios productores mexicanos.

8 Como fueron loscasos de las empresas Estrella Nueva, queabsorbió a sus productores socios mexicanos, y M uranaka Farms, que termina su relación con la empresa Agrícola Las M ontañas, la cual, a su vez, realizó una nueva alianza, de la que se divorció años más tarde para formar Agrícola La Grana, generando así tres nuevas empresas. 


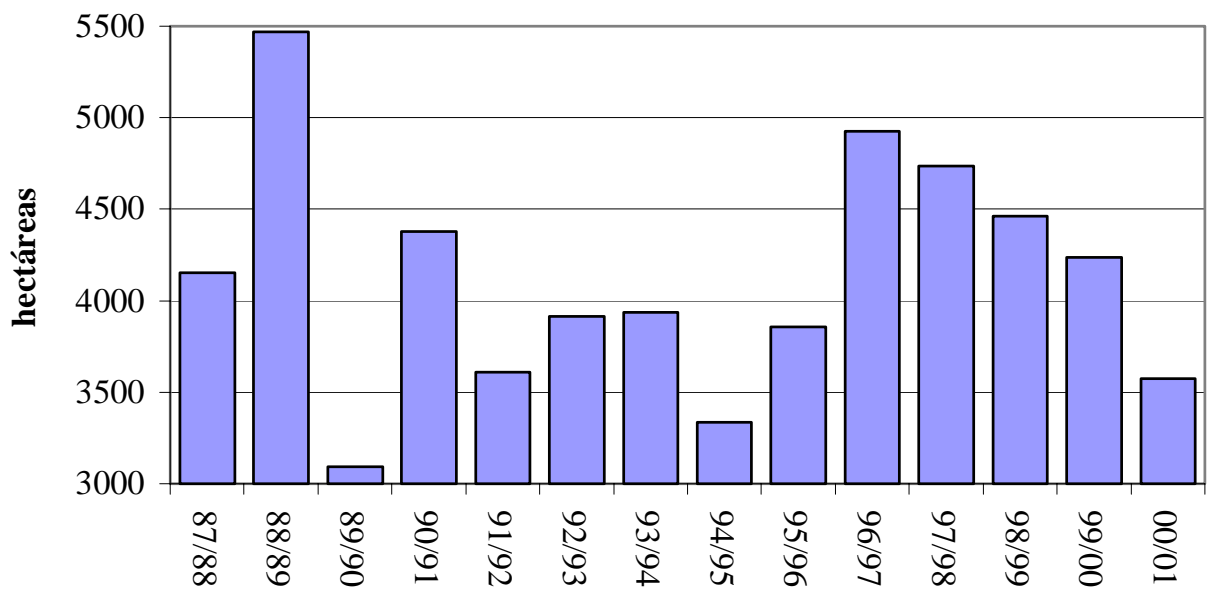

Figura 2. Superficie sembrada de cebollín en el valle de Mexicali, ciclos 1987-1988 a 2000-2001.

Fuente: elaboración propia con base en datos de la delegación de SAGARPA, 2002. Evaluación de la producción agrícola, 1987-2001, y del Sistema Producto Cebollín.

do, crisis que se acrecentó por la subvaluación del peso. Durante ese periodo hubo precios promedio de mercado por debajo de 3.50 dólares por caja, con los cuales no cubrían siquiera los costos de producción, calculados en 5 dólares por caja (Figura 3).

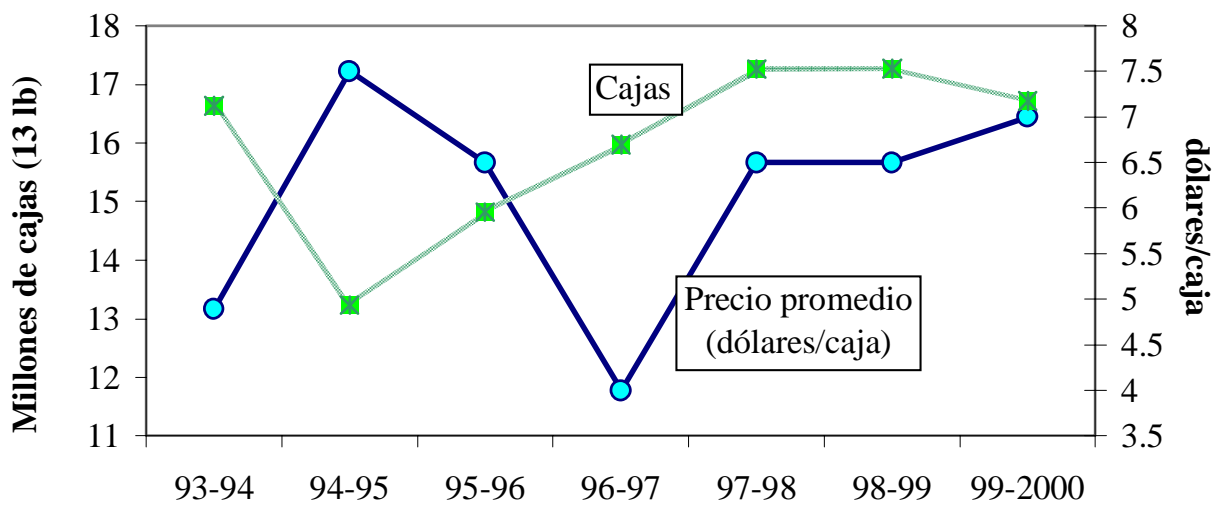

Figura 3. Cajas de cebollín exportadas y precio promedio, 1993-1994 a 1999-2000.

Fuente: elaboración propia con datos de USDA/AMS, http://www.ams.usda.gov/mnreports

Fue entonces cuando los productores tomaron la decisión de organizarse en torno al Sistema Producto Cebollín, formato de asociación que la Secretaría de Agricultura y Recursos Hidráulicos utilizaba en esa época para que los productores de una cadena resolvieran los problemas inherentes a su actividad. Una característica del sistema era la integración voluntaria. Así, después de arduas negociaciones entre los integrantes, determina- 
ron reducir $20 \%$ la superficie sembrada de cebollín, tomando como base la usada históricamente por cada productor, a fin de disminuir la sobreoferta y estimular el precio de venta en el mercado internacional.

Además, se contaba con un análisis del mercado, realizado por la Unión Agrícola Regional de Productores de Hortalizas del Valle de Mexicali, ${ }^{9}$ en el cual se determinaba que el cebollín se enfrentaba a un nicho con poco crecimiento, que sólo permitía la introducción de 400000 cajas por semana (1 600000 por mes) para no provocar el desplome del precio del producto por la sobreoferta. Una vez superado este volumen, el precio caía, por la inelasticidad de la función de oferta. Cuando se exportaban 400000 cajas por semana, el precio de cebollín se mantenía entre 7 y 8 dólares por caja, y cuando la oferta subía a 500000 por semana, el precio descendía a 5.50 dólares; con 600000 cajas bajaba el precio a 3.50 dólares. El mercado se saturaba con más de 600000 cajas por semana, provocando que el precio promedio se situara entre 2.50 y 3.00 dólares por caja.

La medida funcionó exitosamente durante las dos siguientes temporadas (de 1994 a 1996), mientras los productores respetaron el acuerdo y redujeron la superficie. Sin embargo, a partir de 1997 ésta se incrementó nuevamente y provocó una drástica caída en el precio, el cual tiende al ajuste durante los años siguientes.

\section{Estrategias para aumentar la competitividad}

Durante los noventa, resaltaron los esfuerzos realizados por las empresas para satisfacer la calidad demandada por el consumidor estadounidense. A principios de la década, algunas empresas iniciaron cambios que les permitieron lograr un diferencial sustancial en el precio del mismo en el mercado (entrevista con Ernesto Moreno Moreno, 2003, véase nota 2). Básicamente, este proceso consiste en separar cebollín del mismo tamaño para hacer manojos o bunches homogéneos; con anterioridad, la mayoría de las empresas no hacía y los manojos llevaban cebollitas de varios tamaños. La selección permitió ofrecer tres tamaños: pequeño, mediano y grande, y alcanzar mayor precio. Con el tiempo, el proceso se fue haciendo extensivo a todas las empresas y, al generalizarse la práctica, el diferencial de precio que se obtenía por esta selección se perdió.

En cuanto a la calidad del cebollín, no existe en México una norma; sin embargo, el acceso al mercado internacional exigió gran flexibilidad para el uso e implantación de paquetes tecnológicos, que se modernizaban conforme el mercado se sofisticaba y se volvía más exigente. Así, un productor mexicano debía trabajar en las mismas condiciones que uno estadounidense para que su producto fuera aceptado, y debía cumplir con las normas de calidad y sanidad observadas en aquel país, respetar el uso de plaguicidas y

9 Estimaciones realizadas por la gerencia de la Unión Agrícola Regional de Productores de Hortalizas del Valle de M exicali.

\section{DeSarrollo}


fertilizantes, y cumplir con los límites de tolerancia establecidos; además de que las inspecciones de calidad y sanidad se aplicaban de manera más rigurosa a los productos mexicanos. Por ello, los empresarios locales que quieran permanecer en el mercado deben poner mucha atención en el cumplimiento de las normas internacionales vigentes para la producción y exportación de hortalizas frescas. El éxito o competitividad de una mercancía en el mercado internacional no sólo depende de ventajas comparativas derivadas de bajos costos, sino también de las estrategias de comercialización y mercadotecnia.

Así, en los noventa el posicionamiento de las hortalizas del valle de Mexicali, particularmente del cebollín, llevó a los productores a buscar la concurrencia en el mercado internacional más allá del ciclo otoño-invierno, como una estrategia para consolidar la oferta durante en un periodo más largo. De esta manera, durante el verano, la migración de los productores a zonas aledañas —especialmente a los valles de Ojos Negros, La Trinidad y Maneadero, en la Zona Costa del estado- les ha permitido mantenerse en el mercado de Estados Unidos, al satisfacer la demanda de sus comerciali-zadores durante todo el año y no sólo temporalmente, como sucedía con la producción de cebollín a inicios de los años setenta.

Como se muestra en el Cuadro 4, la superficie sembrada en el ciclo primavera-verano cobró mayor importancia a lo largo del periodo 1990-2000; sin embargo, también sufrió los altibajos de un mercado en el cual los volúmenes están determinados por los comercializadores y no por los productores, ya que éstos actúan solamente como tomadores de precios.

Cuadro 4

Superficie sembrada de cebollín en el valle de Mexicali y en la Zona Costa (hectáreas) 1990-2000

\begin{tabular}{cccc}
\hline Periodo & $\begin{array}{c}\text { Ciclo otoño- } \\
\text { invierno }\end{array}$ & $\begin{array}{c}\text { Ciclo primavera- } \\
\text { verano }\end{array}$ & Total $(1)$ \\
\hline $1990-1991$ & 2700 & 1679 & 6297 \\
$1991-1992$ & 2682 & 929 & 6131 \\
$1992-1993$ & 2931 & 981 & 6309 \\
$1993-1994$ & 3188 & 746 & 5693 \\
$1994-1995$ & 2299 & 1038 & 4756 \\
$1995-1996$ & 3378 & 477 & 4930 \\
$1996-1997$ & 3814 & 1112 & 6541 \\
$1997-1998$ & 3780 & 957 & 6061 \\
$1998-1999$ & 3850 & 611 & 5476 \\
$1999-2000$ & 3193 & 1043 & 5256 \\
\hline
\end{tabular}

(1) La diferencia corresponde al valle de San Luis Río Colorado, Sonora.

Fuente: información proporcionada por la Unión Agrícola Regional de Productores de Hortalizas del Valle de Mexicali. 


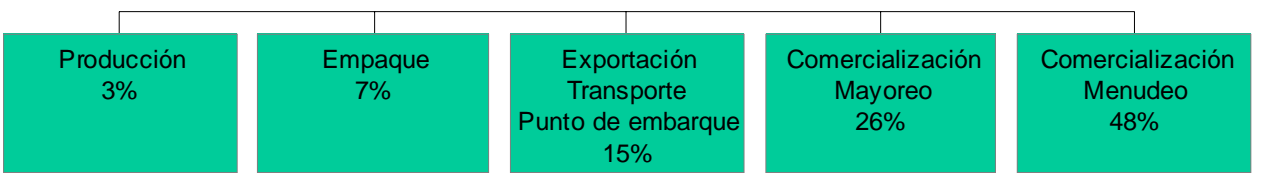

Figura 4. Distribución porcentual de la cadena de valor en la producción de hortalizas.

Fuente: Lugo, S. et al., Estructuras de mercado, encadenamiento del cebollín, Simac-Fundación Produce, Baja California, 2003.

\section{De la monoexportación a la diversificación de la oferta}

Los productores del valle de Mexicali aprendieron que no bastaba un solo cultivo para competir en el mercado internacional y que la oferta de una combinación de ellos tiene como resultado un mejor precio, aun para quienes enfrentan precios a la baja, ya que se amplía la capacidad de negociación de las empresas. De ese modo, en esta etapa se pasa de la monoproducción a la diversificación de la cédula exportable.

En los inicios de la producción en el valle, una empresa exportaba en promedio una sola variedad de hortaliza; ahora, tres tipos, entre las cuales destacan cebollín, rábano, espárrago, cilantro y perejil.

Durante el periodo 1990-2000, los productores no mejoraron su capacidad para la comercialización de las hortalizas en el mercado internacional; sin embargo, lograron integrar un eslabón en su cadena productiva al establecer instalaciones de empaque y sistemas de conservación refrigerados, y en algunos casos en transporte, lo cual les permitió concentrar su oferta y actuar como embarcadores, incrementando su participación en la cadena de valor generada (Figura 4).

De esta manera, los productores se sitúan en la tercera etapa de la cadena y perciben hasta $25 \%$ de la generación de valor por concepto de producción, empaque, embarque y exportación del producto. No obstante, las etapas en las que se genera mayor porcentaje de valor siguen estando en manos de estadounidenses. Nuestros productos continúan entrando a Estados Unidos con marcas comerciales de esa nación, lo cual inhibe su posicionamiento como producto mexicano.

Los comercializadores de Estados Unidos siguen actuando como proveedores de insumos y empaque. En este periodo se sustituyeron los contratos de producción por una forma moderna de financiamiento, mediante el aval de esas compañías a su contraparte mexicana ante los bancos estadounidenses, y por medio del pick and pack, el cual representa una forma de financiamiento al capital de trabajo necesario durante la cosecha. Las liquidaciones se siguen enviando al final de ésta, lo que dificulta al productor tener una percepción real del precio que recibe por su producción.

En esta etapa, de 1990-2000, se registran los primeros requerimientos de certificaciones. La confirmación "libre de residuos de plaguicidas y fertilizantes" es una de las primeras exigencias de esta actividad que requiere Estados Unidos. 
En cuanto a innovaciones tecnológicas en la producción de hortalizas, los primeros cambios se registran en el tipo de riego, que pasó a ser por goteo y aspersión, aunque la mayoría de los productores sigue usando el riego rodado. El riego por goteo y el riego por aspersión han sido incorporados para hacer más óptimas, por una parte, el agua y, por la otra, la aplicación y dosificación correcta de los fertilizantes.

En la línea de empaque se inicia la sustitución de los equipos de hierro común por los de acero inoxidable y fibra de vidrio. Con el paso del tiempo se ha encontrado que esta última es más costosa, dado que su exigencia de mantenimiento es mayor y su vida útil menor; el acero es ampliamente recomendado, por su fácil limpieza y menor riesgo de contaminación.

En este periodo, las principales innovaciones en el manejo poscosecha, aplicada inicialmente por las grandes compañías se relacionan con el uso de técnicas como: a) Hydrocooler, la cual consiste en enfriar el producto con agua hasta $40^{\circ} \mathrm{F}, \mathrm{y}$ b) Hydrovacuum, que trabaja mediante la absorción del aire caliente por un proceso de succión; adicionalmente se inyecta frío al producto, ya sea a través de aire o de agua, y $c$ ) el método de reposo, que estriba en dejar el producto en un cuarto frío por doce horas y someterlo a una etapa final usando agua más fría que la temperatura del producto en reposo. Cabe resaltar que la mayoría de las empresas emplean hielo como principal tratamiento.

\section{De la consolidación a la integración: calidad, sanidad e inocuidad}

A partir del año 2000 se imprime un sello distintivo a la producción de hortalizas: calidad, sanidad e inocuidad son elementos fundamentales e indispensables para la exportación y para la permanencia e incursión en nuevos mercados internacionales. El productor actual se enfrenta a un mercado que exige, cada vez más, mercancías diferenciadas. Productos iceless, inocuos, certificados, orgánicos, con atributos especiales, son requeridos para permanecer en el mercado. Ante el surgimiento de un consumidor exigente, enterado, con conocimiento y conciencia de los alimentos que ingiere, la inocuidad se plantea como necesidad primordial para la aceptación de los productos hortícolas.

Han logrado permanecer hasta la actualidad alrededor de 25 empresas mexicanas, de las cuales $40 \%$ son grandes, con superficies de cultivo mayores a 300 ha, y $60 \%$ son compañías medianas, que cultivan superficies en el rango de 100 a 300 ha. Éstas exportan, en promedio, una canasta de seis tipos de hortalizas: cebollín, rábano, cilantro, perejil, espárrago, leek (poro) y quelites. Sin embargo, en el valle de Mexicali se manejan más de 40 variedades para la exportación.

La producción orgánica se ha convertido en una opción importante en este proceso de diversificación. Las empresas que concurren a este mercado han establecido dos operaciones paralelas, lo cual les permite, al mismo tiempo, certificar la producción orgánica y continuar con la producción convencional. La producción orgánica abarca desde produc-

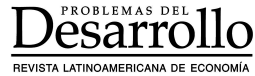


tos como cilantro, perejil, mitzuna y red mustard, hasta los más conocidos: tomate, lechuga, calabaza, berenjena y sandía, entre otros. Aunque la producción orgánica abarca cerca de $25 \%$ de la superficie total orientada a las hortalizas ${ }^{10}$ este tipo de cultivo puede marcar la diferencia entre una buena y una mala temporada, ya que el diferencial de precios respecto de la producción convencional generalmente duplica su valor.

Sin embargo, en la actualidad la actividad sigue arrastrando problemas añejos, como la sobreoferta. En el ciclo agrícola 2000-2001 se establecieron 3214 ha de cebollín, que representaron la exportación de 20970 millones de cajas; en el ciclo 2001-2002, la superficie cultivada con cebollín alcanzó las 4370 ha y una exportación de 22463 millones de cajas; para el 2002-2003 se establecieron 4600 ha con un avance de 13870 millones de cajas al 15 de marzo de ese año.

Este incremento en la producción y exportación de cebollín provoca de nuevo una sobreoferta, con la consecuente depreciación (3.50 dólares/caja), sólo que ahora un acuerdo de reducción de superficie no parece ser suficiente para enfrentar esa sobreproducción, pues mientras el sistema producto no estaba operando - lo cual dificulta la toma de decisiones por parte de los productores - las empresas han incrementado sustancialmente su productividad de 3000 cajas por ha promedio, de principios de los noventa, a cerca de 4000 cajas en los últimos años. A finales de 2002 se reactivó de nueva cuenta el Sistema Producto Cebollín a solicitud de los productores, para la implantación de alternativas a la sobreproducción; sin embargo, ante la falta de un mecanismo coercitivo, los esfuerzos para la planificación de la cédula de cultivo fracasaron, lo cual obligó a los productores a enfrentar un nivel de precios como los registrados en 1993.

Por otra parte, la búsqueda de la desestacionalización de la producción ha llevado a un número reducido de empresas a ampliar sus operaciones, ya no sólo a la Zona Costa del estado, sino a otros estados vecinos, como Sonora y Sinaloa, ${ }^{11}$ para complementar su producción con variedades de hortalizas que no son aptas para el suelo local, pero son importantes para la consolidación de la oferta. Ejemplo de estos productos son col de Bruselas, gay lan, tomate, espárrago, diferentes tipos de chiles (jalapeño, campana, cascabel y mora), chícharo, pepino, diferentes tipos de calabazas [pato, estrella, zucchini (variedad italiana)], sandía y melón de verano.

Cambios importantes en el manejo poscosecha se observan en este periodo. Por ejemplo, se detecta una segunda etapa en la diferenciación del producto, mediante el uso de empaque iceless (sin hielo). Esta técnica consiste en empacar al vacío en el cuarto frío, a una temperatura entre 3.3 y $4.5^{\circ} \mathrm{C}$. Así procesado, el producto no requiere hielo para su conservación y transporte. El nuevo proceso ha implicado también un cambio en el empaque,

10 Para el ciclo 2002-2003 la UARPH estima cerca de 10000 ha dedicadas a la producción de hor talizas.

11 Algunas empresastienen operaciones en M aneadero, Ojos Negrosy el Valledela Trinidad en la Zona Costa del estado; en Caborca (espárrago, principalmente) y Guaymas, Sonora; Empalmey Los M ochis, Sinaloa.

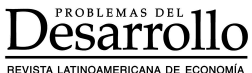


ahora en bolsas de polietileno selladas, en presentaciones de seis onzas (de ocho a diez cebollitas), tres mazos (de seis cebollitas cada uno), una o dos docenas de producto suelto. El método iceless se utiliza también en el rábano y se espera que se extienda a otros productos.

Además de esta técnica, en términos generales se presenta una tendencia a la sustitución del hielo en la conservación del producto final para su transporte. Hortalizas como el espárrago y las cucurbitáceas (calabazas) se manejan sin hielo, pero reciben un tratamiento de hidroenfriado a temperatura de $42^{\circ} \mathrm{F}\left(5.5^{\circ} \mathrm{C}\right)$, enfriado al vacío o una combinación de ambos. Para este fin se usan, además, otras técnicas, como la cámara de enfriado, enfriado al vacío con rocío de agua, enfriado con evaporación y enfriado con aire a presión.

En la distribución de la producción, el transporte es quizá uno de los aspectos más importantes. Es por eso que muchas empresas han considerado la necesidad de adquirir equipo de transporte propio, para poder garantizar el arribo en buen estado del producto al mercado. En esta etapa, el uso de equipo de refrigeración de alta eficiencia es un elemento clave que los productores han asimilado dentro del proceso de integración vertical de la actividad.

La aplicación de estás innovaciones tecnológicas ha tenido un impacto positivo en la comercialización del producto, por su mejor posicionamiento en el mercado y mejor precio. Las empresas que han implantado innovaciones tendientes al cumplimiento de la conformidad — como la certificación de residuos, inocuidad alimentaria o productos orgánicos - tienen mejores condiciones para negociar precios. Por ejemplo, un producto empacado iceless recibe un precio alrededor de $30 \%$ superior a uno regular, y su costo de producción es cerca de $25 \%$ menor que el producto estándar. Un empaque de este tipo implica una reducción en el uso de hielo, caja, papel, ligas y otros aditamentos, pero exige la participación de personal capacitado y de equipo especial apropiado para bajas temperaturas - se debe acondicionar una cámara refrigerada casi de manera exclusiva para este proceso-, lo cual implica nuevas inversiones en infraestructura y equipamiento.

Por otra parte, la certificación de inocuidad es en la actualidad el requisito indispensable para permanecer en el mercado. El cumplimiento de las buenas prácticas agrícolas tanto en la producción en campo como en el de empaque es condición imprescindible para que una empresa pueda certificar su producción en condiciones de inocuidad. Sin embargo, no existe en nuestro país un organismo certificador que esté reconocido por los gobiernos de los países a los que exportamos hortalizas, por lo que la certificación es realizada actualmente por empresas estadounidenses. El cumplimiento con el programa de inocuidad alimentaria instaurado por Estados Unidos a partir de 1998 implica un costo adicional para los productores mexicanos, ya que esta certificación es actualmente exigida por la mayoría de los distribuidores en ese país. Las inversiones que las empresas mexicanas tienen que realizar para acondicionar sus instalaciones y estar en posibilidades de cumplir con dicha iniciativa son altas, pues alcanzan —en el caso de los productores de cebollínrangos de entre 700000 y 2500000 de dólares, por lo que no todos los productores, 
especialmente los pequeños, pueden implantar el programa en el corto y mediano plazo, lo cual implica su desplazamiento del mercado internacional.

A la fecha, esta certificación no genera un diferencial en el precio de los productos en el mercado, pero es una condición exigida por los compradores, por lo cual se espera que mientras las empresas aplican todas las medidas para poder incorporarse al proceso de certificación, podrían perder sus mercados en beneficio de aquellas que ya hayan cumplido con la condición. Por ello, el programa de inocuidad alimentaria se prevé como el principal obstáculo para los exportadores mexicanos de frutas y hortalizas frescas. Si bien Estados Unidos es el primer país en lanzar la iniciativa de inocuidad alimentaria, la cual afecta no sólo el consumo doméstico sino también las importaciones, Europa no se rezaga y presenta Eurepgap, ${ }^{12}$ un programa que busca sentar las bases para el establecimiento de buenas prácticas agrícolas, en el cual se definen los elementos esenciales para el desarrollo de una más eficiente producción global de productos hortofrutícolas.

Tanto las buenas prácticas agrícolas estadounidenses como las europeas tienen como fundamento científico la reducción al mínimo del riesgo microbiológico de contaminación y la sugieren su aplicación a todos los productores de frutas y hortalizas frescas. Así, los productores mexicanos enfrentan un nuevo reto para permanecer en el mercado internacional de alimentos.

\section{Identificación de la cadena agroalimentaria del cebollín y relaciones que existen entre sus eslabones}

Para complementar el análisis de la producción de hortalizas en el valle de Mexicali y su competitividad en el mercado de exportación, se elaboró la matriz FODA (fortalezas, oportunidades, debilidades y amenazas), que sintetiza la principal problemática detectada en cada una de las etapas que conforman el eslabonamiento productivo del cebollín, desde la producción hasta la comercialización (Cuadro 5). Cabe señalar que las mismas condicones imperan para la generalidad de las hortalizas que se producen en el valle.

La cadena agroalimentaria está integrada por los agentes y actividades económicos que intervienen en su proceso productivo, desde la provisión de insumos y materias primas hasta la transformación o preparación para su consumo. De acuerdo con las características del producto, el cebollín se vende fresco, por lo que, en comparación con otros bienes agroalimentarios, su cadena es más corta.

Otra característica de este producto es que está integrado al mercado internacional (específicamente el estadounidense), lo cual provoca dependencia tanto hacia atrás (por el abastecimiento de insumos que, en su mayoría, son de origen o importados de Estados

12 Más detalles se pueden consultar en: $h$ ttp:// www.sica.gov.ec/agronegocios/ productos\%20para\%20 invertir/ organicos/ Eurepgap.htm; y http://www.eurep.org/sites/index_e.html

\section{$\frac{\text { DeSRarrollo }}{\text { PRoB LEMAS DEL }}$}


Unidos), como hacia delante, en el mercado, con gran concentración en el ya citado. Esta circunstancia puede generar problemas o cuellos de botella, ya que $90 \%$ de las exportaciones son destinadas a un mercado donde los detallistas y las grandes cadenas de supermercados controlan la mayor parte de la comercialización.

La principal fortaleza del producto se encuentra precisamente en su producción, que cumple con los más altos estándares de calidad, sanidad e inocuidad requeridos internacionalmente, y su principal oportunidad es concurrir a nuevos mercados con una calidad comprobada. Su principal debilidad se localiza en el proceso de comercialización, al que no se han podido integrar los productores desde el inicio de la actividad, y la principal amenaza la constituyen otros países, como Guatemala, que están incursionando en la producción de cebollín, aunque en escala pequeña.

1. Fortalezas

a) Producción de clase mundial. Cumple con las especificaciones de calidad que requieren los productos de exportación.

b) Gran integración vertical de la producción, lo que permite al productor tener control de la calidad en todas las etapas del proceso.

c) Ventaja competitiva respecto del principal competidor por costos, disponibilidad de mano de obra y cercanía al mercado destino.

\section{Oportunidades}

a) Diversificación de la producción.

b) Concurrencia a otros mercados internacionales.

c) Desarrollo de marca y posicionamiento del producto en otros destinos.

d) Integración horizontal de la producción mediante el desarrollo de proveedores.

\section{Debilidades}

a) Extrema dependencia de insumos importados.

b) Concentración de las exportaciones en un solo mercado.

c) Dependencia en la comercialización del producto.

\section{Amenazas}

a) Concurrencia de otros países al mercado de destino.

b) Posicionamiento de la inversión extranjera en detrimento de la nacional.

Como se puede observar en la Matriz foDa (Cuadro 5), las empresas productoras de hortalizas del valle de Mexicali no están exentas de la problemática que aqueja a otras regiones del país, sin embargo, su competitividad se ha asentado en factores microeconómicos que les han permitido mantenerse en el mercado internacional. El bajo nivel educativo de

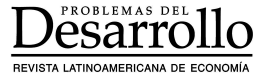




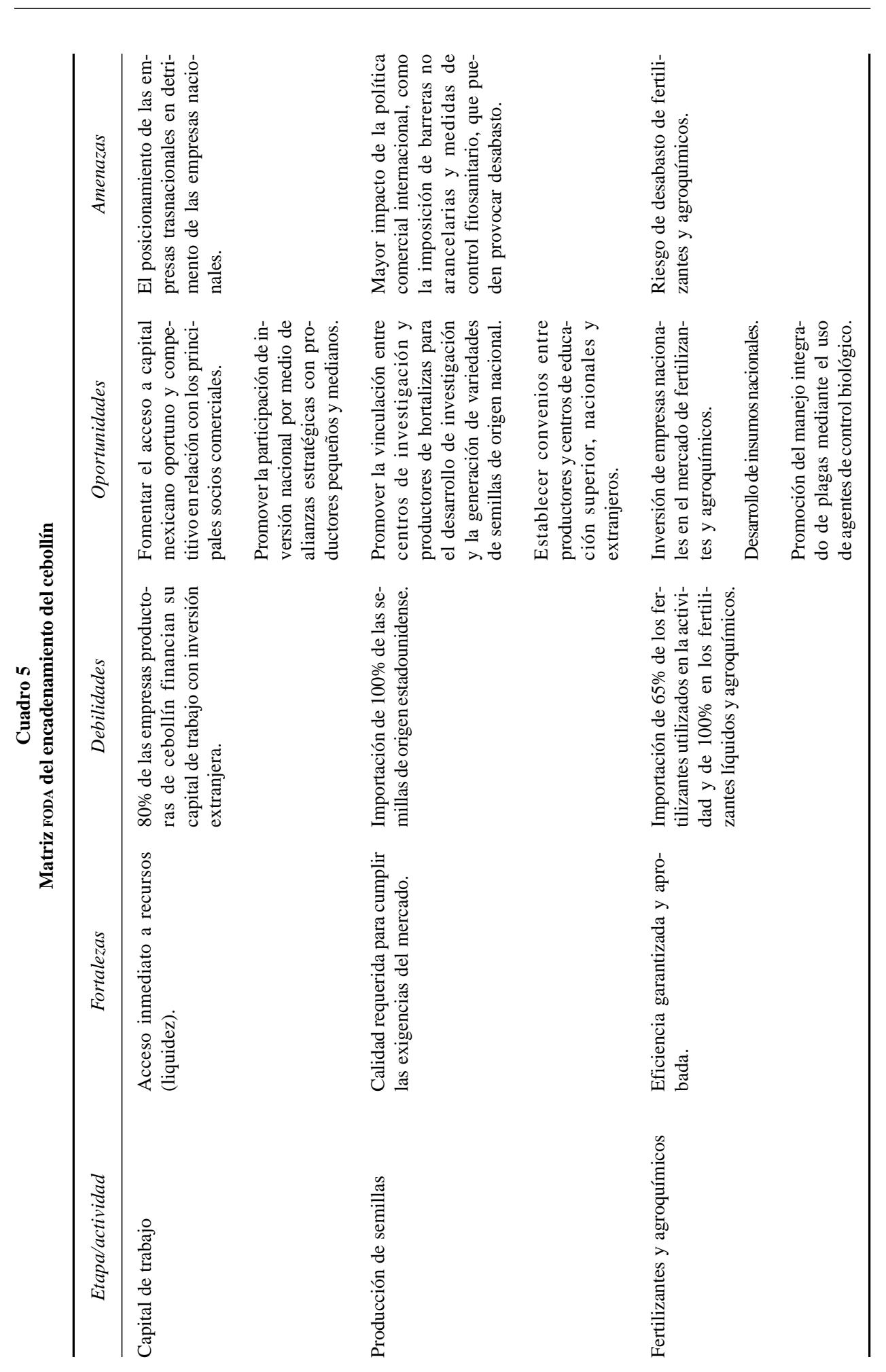

Deesarrs rollo 


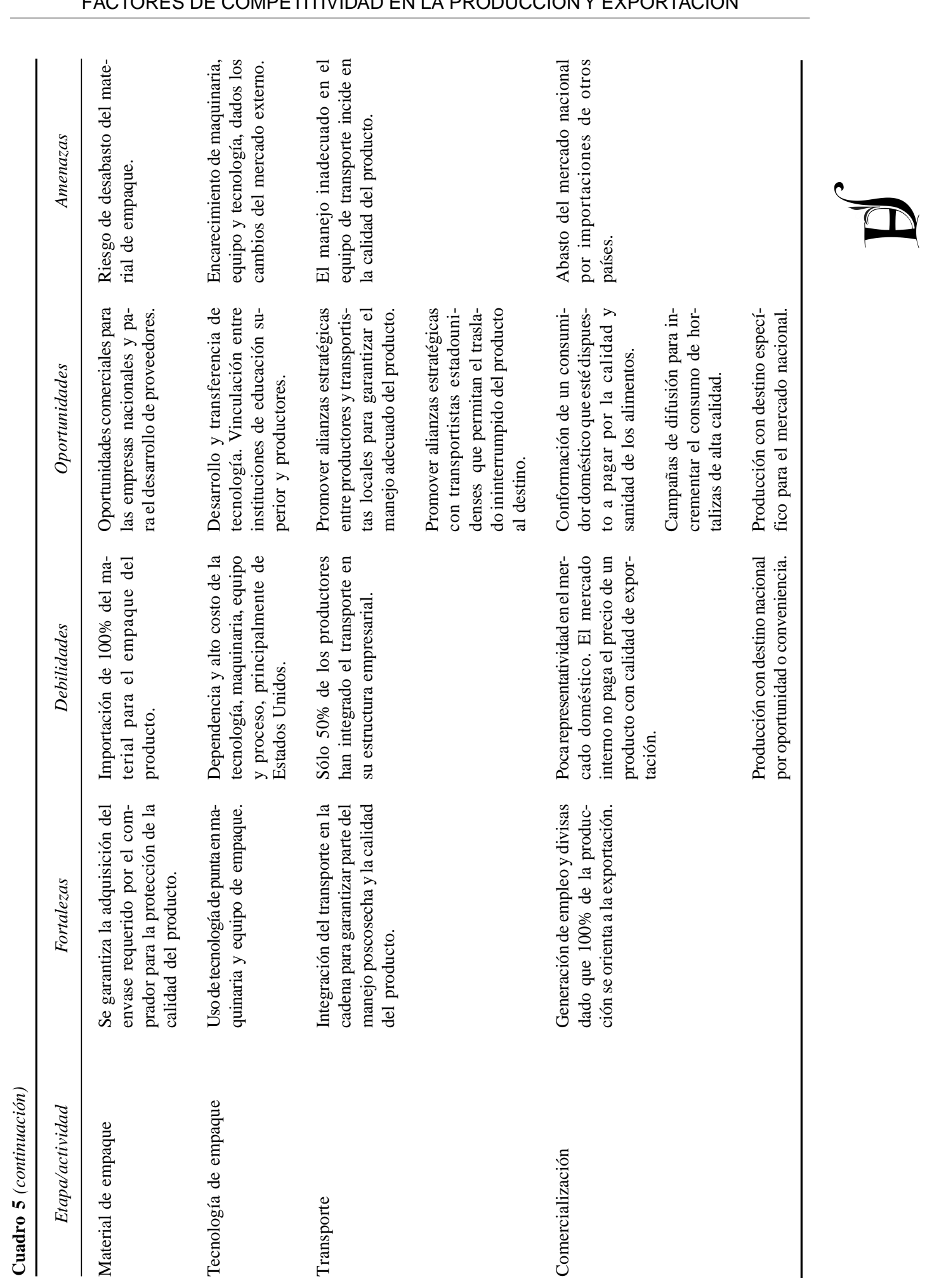

Deesosaras on 


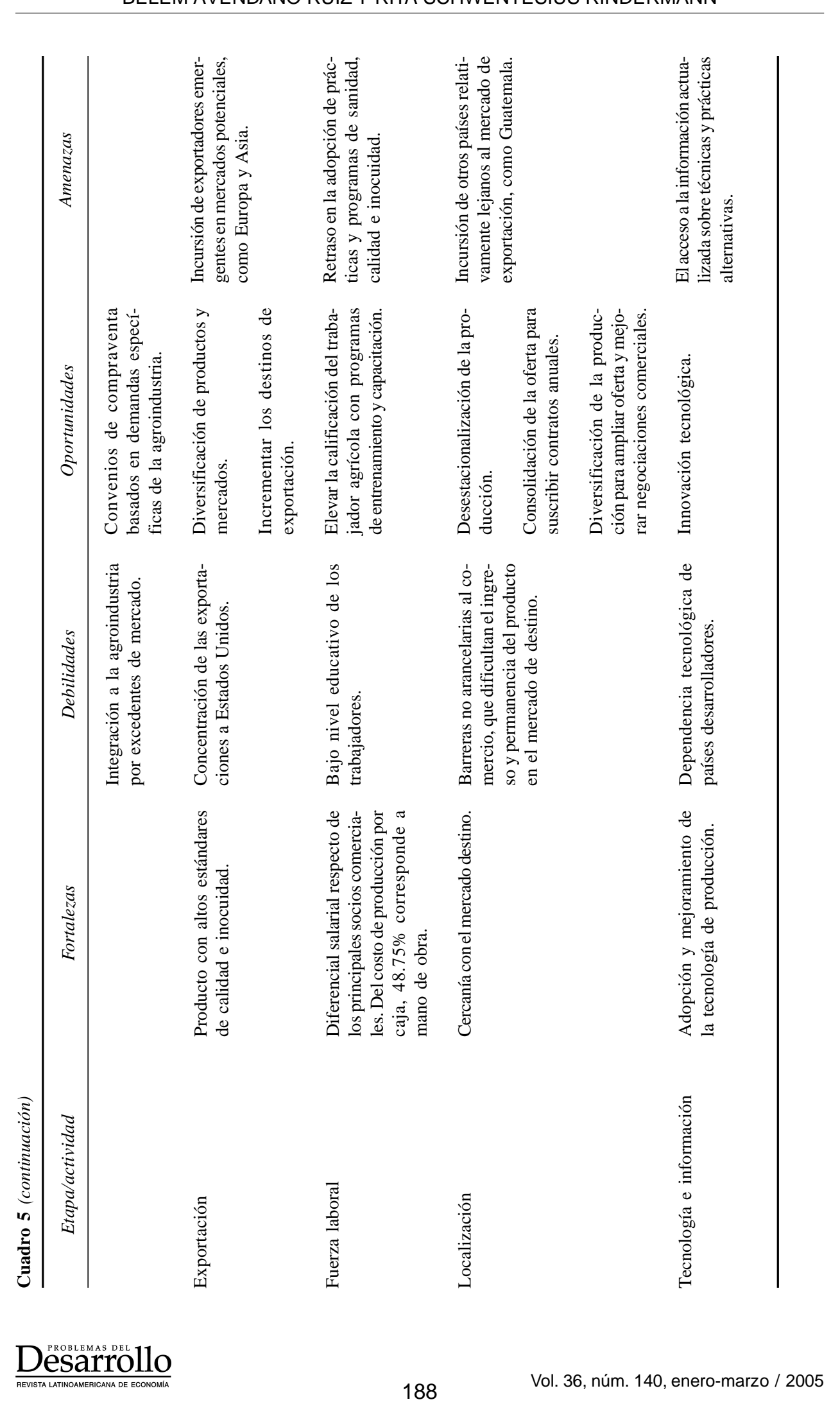




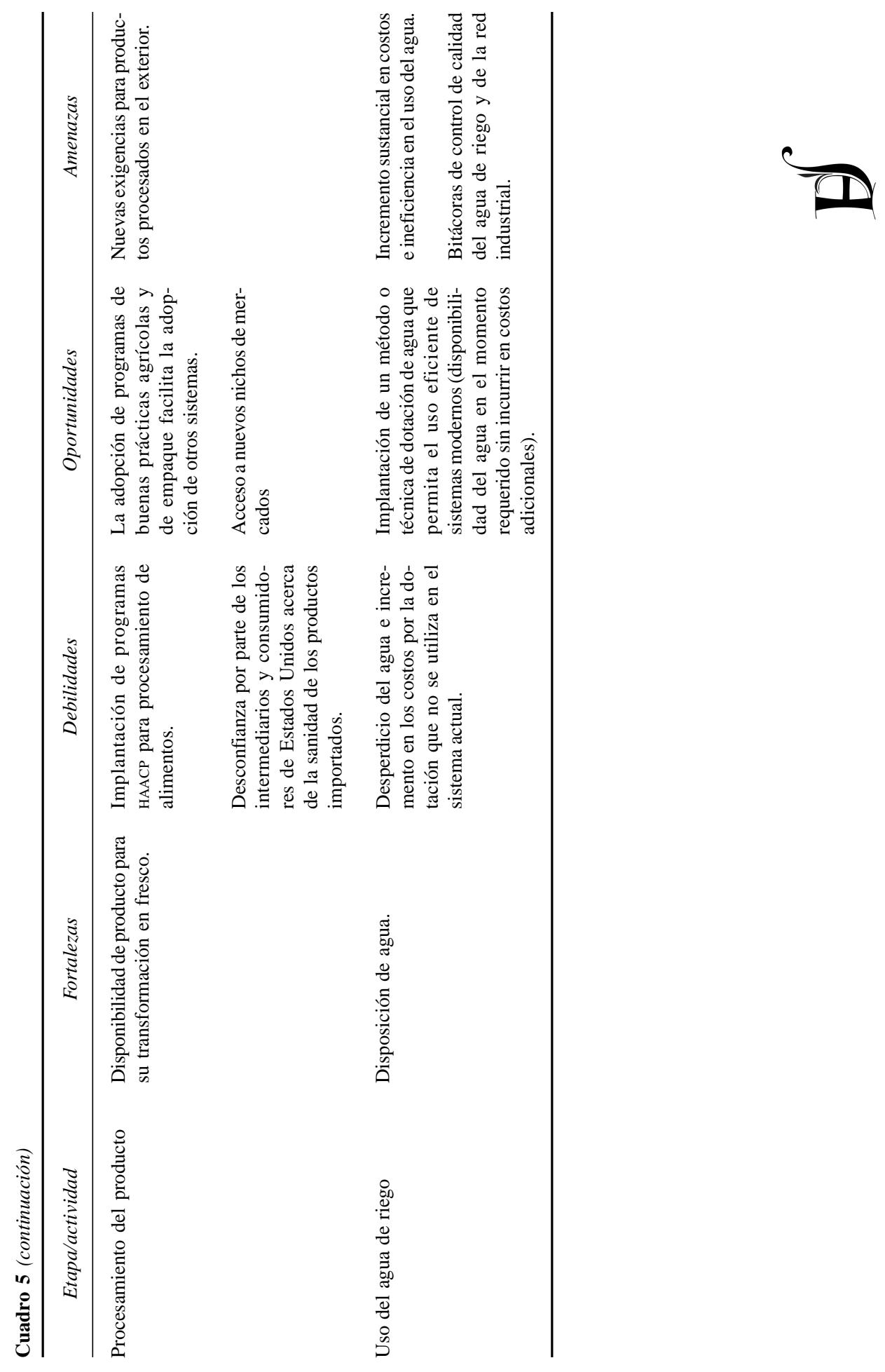


los trabajadores, la falta de una política agrícola con rumbo, subsidios y apoyos directos al campo en condiciones similares a nuestros competidores, el oneroso acceso al crédito, la poca responsabilidad del gobierno en el control de la calidad del agua, el pobre desarrollo de la investigación y la transferencia de tecnología, en fin, la falta de apoyo institucional para desarrollar integralmente al sector provocan que esta cadena no genere una derrama económica (spillovers) sustanciosa para la economía regional y nacional.

Como complejo productivo, en el valle de Mexicali esta actividad no logra sobrepasar la primera fase, en la cual el producto se exporta sin procesamiento, los insumos y la maquinaria son importados, al igual que la ingeniería en producción y diseño de proyecto. Sumamente difícil se vislumbra el acceso a la segunda fase, en la cual se inicia un primer nivel de procesamiento y se genera la sustitución de importaciones de insumos principales y de maquinaria. Mientras no se diseñe una política agrícola acorde con las necesidades regionales y nacionales, y con un modelo de país, la dependencia de los grandes mercados seguirá, con la consecuente vulnerabilidad de los ciclos económicos de nuestros grandes socios comerciales, de quienes somos sólo los proveedores de productos agrícolas cuando así conviene a sus intereses.

\section{Conclusiones}

La competitividad de un producto en el mercado internacional no es cuestión de suerte. Los factores que inciden en aquélla son de naturaleza diversa y van desde el entorno institucional hasta cuestiones de organización de los productores. Sin embargo, la permanencia en el mercado internacional implica que éstos sean cada vez más competitivos e implanten estrategias que les permitan sostenerse en un entorno cada vez más regulado. La simple cercanía con un mercado ya no es garantía de acceso. La complementariedad con éste ya no es cuestión de la naturaleza. Los ciclos agrícolas se alargan y la producción se desestacionaliza.

Los productores tienen que organizarse para enfrentar los vaivenes del mercado. La globalización no conoce fronteras y la concentración de la oferta en un solo mercado lo vuelve tan vulnerable, que el establecimiento de una regulación puede actuar como una barrera técnica al comercio y desplazarlo del mismo.

La participación en sólo una parte de la cadena agroalimentaria deja al productor a merced de los comercializadores, quienes obtienen el mayor porcentaje de los ingresos generados. Mientras el productor no logre concurrir al mercado como distribuidor, los intermediarios ganarán la mejor tajada.

Actualmente, es sumamente difícil disminuir los costos de producción para competir en precio ante el surgimiento de nuevos programas como el de inocuidad alimentaria, que les obliga a mejorar su estructura productiva, realizar nuevas inversiones e incrementar su productividad. El problema no radica en alcanzar estos objetivos, sino en la falta de apoyo

\section{$\underline{\text { DeSarrollo }}$}


institucional para el sector. La producción de hortalizas para la exportación requiere de la apertura de nuevos mercados, de la consolidación de una oferta exportable que permita a los productores negociar mejores precios, de la diversificación de la oferta, de la transformación de la producción para agregar valor, de una intensa campaña de mercadotec-nia que logre posicionar los productos mexicanos en el extranjero, y de un gobierno comprometido con la defensa de los intereses de sus exportadores, que los apoye con la definición de estrategias para alcanzar y mantener su competitividad internacional.

Los productores enfrentan mayores retos y la misma problemática. En el valle de Mexicali el cultivo de hortalizas presenta una gran fortaleza en la producción, pero una gran debilidad en la comercialización. A pesar de ser la región en la que se produce todo el cebollín que México exporta a Estados Unidos, los productores continúan actuando como tomadores de precios y no como fijadores, y no han logrado mejorar la capacidad para distribuir su producción en los mercados internacionales. Los comercializadores de los productos hortícolas mexicanos siguen siendo los estadounidenses, quienes han sabido aprovechar la competitividad de nuestras hortalizas y posicionarlas bajo sus propias marcas. ¿Quién podría distinguir un cebollín mexicano en una caja de Fresh kist, River Ranch, Omo, New Star o de cualquier otra marca estadounidense?

\section{Cuadro 6}

Principales cambios tecnológicos asociados con la producción de hortalizas para exportación en el valle de Mexicali

\begin{tabular}{|c|c|c|c|}
\hline Concepto & $\begin{array}{c}\text { Periodo } \\
\text { inicial 1970-1987 }\end{array}$ & $\begin{array}{l}\text { Consolidación } \\
\text { 1988-1997 }\end{array}$ & $\begin{array}{l}\text { Integración } \\
1997-2003\end{array}$ \\
\hline $\begin{array}{l}\text { Producción/ } \\
\text { rendimientos }\end{array}$ & 2500 cajas/ha & 3000 cajas/ha & 4000 cajas/ha \\
\hline Amarre & Liga & Liga & Liga y alambre con código de barras \\
\hline Empaque & Caja con hielo & Caja con hielo & $\begin{array}{l}\text { Iceless, bolsas de polietileno y cajas } \\
\text { de polipropileno }\end{array}$ \\
\hline $\begin{array}{l}\text { Tratamiento } \\
\text { poscosecha }\end{array}$ & EH & $\mathrm{EH}, \mathrm{HE}, \mathrm{AP}$ & $\mathrm{HE}, \mathrm{AP}, \mathrm{CA}, \mathrm{EV}, \mathrm{EVA}, \mathrm{EE}$ \\
\hline Instalaciones & Fierro & Acero inoxidable & Acero inoxidable, fibra de vidrio \\
\hline Calidad de agua & Sin tratamiento & Ósmosis & Ósmosis y ozono \\
\hline Certificaciones & RPF & RPF y orgánicos & RPF, órgánicos, inocuidad \\
\hline Exportación & Una variedad de hortaliza & $\begin{array}{l}\text { Tres variedades } \\
\text { de hortaliza }\end{array}$ & Seis variedades de hortaliza \\
\hline
\end{tabular}

CA: cámara de enfriado; HE: hidroenfriado; EVA: enfriado al vacío con rocío de agua; EV: enfriado al vacío; EH: empaque hielo; EE: enfriado con evaporación; AP: enfriado con aire a presión. RPF: residuos de plaguicidas y fertilizantes.

\section{$\underline{\text { DeSarerrollo }}$}




\section{Bibliografía}

Colmenares, V.J.H., "Anotaciones generales sobre los factores que afectan la competitividad", en Posibilidades para el desarrollo del campo mexicano, t. I, México, Cambio xxi, 1996, pp. 37-53.

Contreras, José María, "La competitividad de las exportaciones mexicanas de aguacate: un análisis cuantitativo", reporte de investigación 46, CIESTAAM-UACH, 2000.

CNPH, "El desarrollo de la comercialización de hortalizas y frutas de México en los Estados Unidos y Canadá", reporte anual/propuesta, 1988-1989.

COPLADEM, Anuario Estadístico de Mexicali, Mexicali, COPLADEM, 2000.

- Anuario Estadístico Municipal, segunda versión CD, Mexicali, COPLADEM, 2002,

FAO, Faostat, http://apps.fao.org

Hernández, Juan Pablo, "Perspectivas de las empresas nacionales dedicadas al cultivo de cebollín en el valle de Mexicali, B.C.", tesis profesional, Tijuana, Instituto de Ciencias AgrícolasUniversidad Autónoma de Baja California, 2002.

\section{Glosario de términos}

Buenas prácticas agrícolas: se refiere a las prácticas generales para reducir riesgos físicos, químicos y microbiológicos en los alimentos, empleados en el cultivo, cosecha, selección y otras actividades realizadas en el campo.

Buenas prácticas de empaque: son las prácticas generales para reducir riesgos de contaminación física, química y microbiológica en los alimentos, realizadas en las actividades de selección, procesamiento, empaque, almacenaje, transporte $\mathrm{y}$ distribución.

Room cooling: (enfriado en cámara): las cajas de productos se estiban en cuartos refrigerados. Algunos productos se rocían con agua durante el enfriamiento.

Hydrocooling (hidroenfriado): los productos se bañan con agua helada (agua con hielo) en cajas, contenedores o tanques.

Hydrovacuum cooling (enfriado al vacío con agua): se añade humedad a los productos empacados en cajas, antes o durante el proceso de aspirado, para acelerar el retiro de calor.

Iceless (empaque sin hielo): proceso de empaque al alto vacío de productos previamente enfriados y en reposo por más de 48 horas, que permite la conservación del producto sin el uso de hielo.
Lugo, S. et al., Estructuras de mercado, encadenamiento del cebollín, Baja California, SimacFundación Produce, 2003.

Ranfla González, Arturo, "Polarización de la producción agrícola y el comercio en la frontera norte", en Cuaderno de Ciencias Sociales, serie 3, núm. 4, IIS-UABC, Tijuana, 1987.

SAGARPA, Evaluación de la producción agrícola, 19872001, Delegación de Baja California, 2002.

Stamatis, Martha, "Los contratos de producción en el noroeste de México: El valle de Mexicali a fines de la década de los ochenta", en Estudios Fronterizos, núm. 30, IIS-UABC, Tijuana, enero-abril de 1993.

Unión Agrícola Regional de Productores de Hortalizas del Valle de Mexicali, reportes internos de trabajo, 2003.

USDA/AMs, http://www.ams.usda.gov/mnreports

Vollrath, Thomas L., "Global Competitive Advantages", Economic Research Service-United States Department of Agriculture, http://usda.mannlib. cornell.edu/data-sets/trade/93005/readme.doc. 1991.

Inocuidad alimentaria: término derivado de acuerdos internacionales para describir la condición de que los productos no presenten riesgo para la salud de los consumidores.

Package-icing (empaque en hielo): se inyecta hielo picado o triturado a cada caja de producto.

Pick and pack (cosecha-empaque): financiamiento otorgado por las empresas distribuidoras, localizadas generalmente en Estados Unidos, a empresas mexicanas para que realicen las actividades de cosecha y empaque.

Traceabilidad o rastreabilidad: es la habilidad de conocer la historia, aplicación o ubicación de un elemento por medio de identificaciones registradas. Se relaciona con el origen de insumos, la historia del procesamiento, la distribución y ubicación del producto después de la entrega.

Vacuum cooling (enfriado al vacío): se remueve el calor de los productos empacados en cajas mediante la instalación de una aspiradora en una cámara.

Forced-air cooling or wet pressure cooling (enfriado con aire a presión o forzado): se circula aire mediante unidades cargadas con cajas de producto en cuartos refrigerados. En algunos productos se añade agua al aire. 